\title{
MODERATE ALCOHOL CONSUMPTION AS A MEDIATOR OF MOTHER'S BEHAVIOUR TOWARDS HER CHILD
}

\author{
Mojmír Tyrlík, Štěpán Konečný \\ Institute for Research on Children, Youth and Family, Faculty of Social Studies, Masaryk University, Brno, Czech Republic
}

\section{SUMMARY}

Aim: The purpose of this study is to examine the effect of moderate drinking on mother's behaviour towards her child.

Method: The European Longitudinal Study of Pregnancy and Childhood (ELSPAC) survey sample consisted of 3,569 Czech women, who were interviewed when their children were 18 months old. There were three areas related to mother child relationship investigated: hygiene, activities with the child, and the mother's emotional relationship with the child. Besides alcohol consumption, we also evaluated the mother's neuroticisms.

Results: Our results suggest that the behaviour of moderate drinking mothers differs from the behaviour of abstaining mothers. The abstinents express more emotions for the child, they handle better the demands of maternity and pay more attention to needs for child's educative activities. Significant differences were not noticed in the frequency of physical activities with the child (cuddling, physical playing, walks).

Conclusion: Our data supports the assumption that moderate drinking of a mother is disadvantageous for the child as compared to abstinence. The abstinents display a higher level of concern about the child.

Key words: moderate drinking, alcohol consumption, women, care about child, emotions, maternity

Address for correspondence: M. Tyrlik, Institute for Research on Children, Youth and Family, Faculty of Social Studies, Masaryk University, Jostova 10, 60200 Brno, Czech Republic. E-mail: tyrlik@phil.muni.cz

\section{INTRODUCTION}

Overuse and addiction to alcohol is a long-term observed psychological, social and health issue. Even though the majority of individual, family and social tragedies caused by alcohol started by a more or less regular consumption of a small amount of alcohol, moderate drinking is not only tolerated but also promoted by society. This does not concern only advertisements for alcohol and companies selling alcohol, but also relatively frequent uncritical promotion of scientific studies dealing with the effect of moderate consumption of alcoholic drinks on the human organism, with allegedly beneficial effect of it, e.g. lowering the risk of ischemic stroke, coronary heart disease and dementia in the later phase of life (1-6). Comprehensive view of this matter is provided by Baum-Baicker (7), who describes five areas of benefits described by people consuming a small amount of alcohol: 1) lower stress, 2) better mood, 3) cognitive performance, 4) lower clinical symptoms - depression in particular, 5) better functioning in older age. Peele and Brodsky (8) state that moderate drinking in comparison with heavy drinkers is connected with psychological, physiological and social feelings of well-being, high spirit, lower stress under certain circumstances, increased sociability and social participation. Results of a prospective Czech study indicate especially the improvement of ability to cope with interactive stressful life events as a reason for consumption of alcohol in the group of studied women (9). However, even moderate alcohol consumption, especially among young women, can easily escalate into heavy drinking and alcohol dependence. The tolerated daily amount of alcohol, of course, differs with every individual. Results of a study Meyerhoff et al. (10) imply that damage of brain tissues and cognitive functions does not occur with usually tolerated alcohol consumption, i.e. less than two drinks a day for a healthy man and one drink for a healthy woman.

Studies dealing with possible influence of the alcohol consumption on fetus in the prenatal period show the explicit hazard of excessive alcohol consumption with respect to fetus size and its abnormalities (11), depressive symptoms (12) or ill neurological effects (13). However, only a small or no effect is found with moderate drinking (14). Results of research dealing with the effect of a mother's moderate drinking on cognitive development, with regards to the child's age in particular, are ambiguous (15). In child psychology, mother and child attachment, influenced by a number of cognitive and emotional factors, is observed in connection with alcohol consumption of the mother. The connection between an insecure mother and child attachment and alcoholism of the father or mother has been proved $(16,17)$. These studies, however, also concentrated mainly on the effect of excessive alcohol consumption.

The aforementioned studies rather separate excessive alcohol consumption from moderate drinking and abstinence, and do not assume continuous transition between these in the sense of harm and consequences. Moderate drinkers sometimes constitute a referential group for determination of excessive alcohol consumption hazards.

The low interest of psychologists as to the consequences of moderate drinking confirms the common perception of moderate 
drinking as a relatively trouble-free phenomenon. Dealing with a small sample it is often impossible to detect the effects of moderate drinking on strange mother's behaviour towards the child as this effect may be rather inessential.

\section{AIMS}

Despite the above mentioned results which show moderate alcohol consumption as a relatively risk-free phenomenon, we should take into account both the specificity of the moderate consumer's personality and tentative change of their mind after alcohol use which could result in behaviour towards their child that is different from abstaining mothers. The aim of this study is to explore the effect of moderate drinking on a mother's behaviour towards her child in a relatively large sample of mothers indulging in moderate alcohol consumption. The behaviour of the mother is assessed in three areas: concern about the child and care of the child's hygiene, common activities with the child and the mother's relationship with the child. Besides alcohol consumption, we also evaluate the mother's neuroticisms and her relationship with her partner as possible co-variates.

\section{METHODS}

Data was obtained in the frame of the European Longitudinal Study of Pregnancy and Childhood research in the Czech Republic, whose sample consists of all children born in the city of Brno (about 300 thousand inhabitants) and country district of Znojmo (about 100 thousand inhabitants) born between March 1st 1991 and June 30th 1992. The sample includes both nulliparas and multiparas. Single mothers and women living without a partner were excluded. Data from 3,388 women obtained when the child was 18 months old were analysed. Questionnaire data was obtained by correspondence. The response rate was about $50 \%$.

An independent variable was categorized depending on the answer to this question: "How often do you drink alcohol?" Three separate groups were sorted by the answer to this question with respect to the regularity and frequency of alcohol drunk. The group of women who do not drink alcohol (captured as abstaining group) consisted of 592 respondents (17.4\%). The group of moderate consumers (2,796 women; $81.6 \%$ ) consisted of women who answered they drink alcohol at most once a week. The third group of 32 women who wrote they usually drink alcohol more frequently was not included into this analysis due to their low number. Age ranged from 16 to 44 years in the abstaining group $($ mean $=24.98$, median $=24)$ and from 16 to 45 years in the moderately drinking group $($ mean $=25.6$, median $=25)$.

The frequency of the mother's care of the child's hygiene (e.g. washing of hands, face, ears and bathing) was found out by the four-points (five-points, respectively) ordinal scales. The frequency of educative activities with the child was expressed by four-points ordinal scale items (e.g. singing with the child, showing pictures in books, playing with toys with the child) as well as common physical activities (e.g. cuddling, clapping and walks with the child).

In order to evaluate mother-child relation we used 22 questions inquiring about reaction of the mother to (having) a tod- dler. Three considerable factors were obtained via the Principal component analysis with the Varimax rotation method. The first factor assessed the maternity burden. It highly correlated with five statements, e.g. "To have a little baby is absolutely exhausting" or "I really cannot stand my baby crying". The second factor relates to the mother's love for the child. It was constituted by five statements, such as "I really love my child." The last one expresses the mother's concerns about the child. It highly correlated with four statements, such as "I often worry whether my child eats enough" or "I worry when somebody else takes care of my child". We used the Regression Method in order to estimate the factors score coefficients. The three new variables have a mean of 0 and variances equal to the squared multiple correlation between the estimated factor scores and the true factor values.

The scales of depression, anxiety and somaticism of the Crown-Crisp Experiential Index were used to assess neurotic symptoms.

We used both MANOVA and the non-parametric Mann-Whitney test when the scales were ordinal. However, we provide means for separate groups of mothers next to the ordinal test statistics for the sake of more comprehensible documentation. Bonferroni correction for multiple measuring was used when necessary. We used SPSS software (16).

\section{RESULTS}

Three groups of women were compared on the basis of frequency of the occurrence of three separate self-reported phenomena, e.g. regularity of care of child's hygiene, home educative activities and physical activities with the child.

Frequency and regularity of care about the child's hygiene differed significantly among the groups in three out of four items (except the washing of hands). The abstinents stated more regular and frequent bathing, hand washing and ear cleaning (see Table 1).

Also, we found significant differences with items expressing home educative activities with the child (singing, showing pictures and playing with toys). The mean value of the frequencies of the mother's activities with the child is higher in the abstinents.

On the other hand, no differences between all three groups were found concerning physical activities with the child (cuddling, clapping, rolling) and frequency of walks.

We compared the groups with respect to three factors concerning the relationship with the child - maternity burden, love for the child and concerns about the child. The neuroticism of mother was included as a covariate in the model. Despite that the effect of neuroticism was robust and significant $F($ d.f. $=3 ; 2995)=14.79 ; p<0.001$, the statistics of abstainers vs. moderate drinkers comparison was convincingly significant in multivariate test $F($ d.f. $=3 ; 2995)=282 ; p<0.001$. Mean values are lower with abstinents then with moderate consumers in the case of burdens experienced by maternity. On the other hand, the means of the love for the child and the concern (worry) about the child are higher in abstaining group. The two groups differ significantly with dimensions burdens by the maternity and concern about the child also when univariate analysis was taken into account (see Table 2). 
Table 1. Mother's activities with child

\begin{tabular}{|c|c|c|c|c|c|}
\hline & & $\mathrm{N}$ & $\mathrm{m}$ & SD & $\begin{array}{c}M-W Z \\
p\end{array}$ \\
\hline \multirow{2}{*}{ Washing of face } & abstinent & 586 & 2.91 & 0.71 & -2.37 \\
\hline & moderate $\mathrm{c}$. & 2.770 & 2.83 & 0.69 & $p<0.05$ \\
\hline \multirow{2}{*}{ Washing of hands } & abstinent & 584 & 3.35 & 0.66 & -1.87 \\
\hline & moderate $\mathrm{c}$. & 2.771 & 3.30 & 0.66 & n.s. \\
\hline \multirow{2}{*}{ Ear cleaning } & abstinent & 588 & 2.90 & 0.88 & -4.14 \\
\hline & moderate $\mathrm{c}$. & 2.780 & 2.73 & 0.84 & $p<0.001$ \\
\hline \multirow{2}{*}{ Bathing } & abstinent & 588 & 3.65 & 0.64 & -3.85 \\
\hline & moderate $\mathrm{c}$. & 2.780 & 3.53 & 0.68 & $p<0.001$ \\
\hline \multirow{2}{*}{ Feeding } & abstinent & 589 & 3.97 & 0.24 & -0.68 \\
\hline & moderate $\mathrm{c}$. & 2.773 & 3.97 & 0.20 & n.s. \\
\hline \multirow{2}{*}{ Singing } & abstinent & 591 & 3.52 & 0.76 & -3.18 \\
\hline & moderate $\mathrm{c}$. & 2.778 & 3.43 & 0.78 & $p<0.001$ \\
\hline \multirow{2}{*}{ Showing pictures } & abstinent & 591 & 3.79 & 0.49 & -3.3 \\
\hline & moderate $\mathrm{c}$. & 2.776 & 3.74 & 0.49 & $p<0.001$ \\
\hline \multirow{2}{*}{ Playing with toys } & abstinent & 590 & 3.77 & 0.51 & -3.57 \\
\hline & moderate $\mathrm{c}$. & 2.779 & 3.71 & 0.50 & $p<0.001$ \\
\hline \multirow{2}{*}{ Cuddling } & abstinent & 591 & 3.92 & 0.33 & -0.34 \\
\hline & moderate c. & 2.778 & 3.93 & 0.27 & n.s. \\
\hline \multirow{2}{*}{ Physical playing (clapping) } & abstinent & 590 & 3.70 & 0.58 & -1.08 \\
\hline & moderate $\mathrm{c}$. & 2.775 & 3.69 & 0.53 & n.s. \\
\hline \multirow{2}{*}{ Walks } & abstinent & 590 & 3.93 & 0.30 & -0.57 \\
\hline & moderate c. & 2.777 & 3.94 & 0.27 & n.s. \\
\hline
\end{tabular}

\section{DISCUSSION}

The stated results confirm the assumption that even moderate drinking influences the behaviour of a mother towards her child even though the differences between abstinent mothers and moderate drinking mothers are subtle. In comparison with moderate drinking mothers, abstinents express more emotions for the child, they handle better the demands of maternity and pay more attention to educative activities with the child. At the same time, abstinents display a higher level of concern about the child's consistent hygiene. On the other hand, no significant differences between moderate drinking mothers and abstinents were noticed with respect to the frequency of physical activities with the child (cuddling, physical playing and walks). We should discuss some possible subsidiary factors that could change the behaviour of moderately drinking mothers other than the alcohol consumption.

One of the possible explanations is the higher occurrence of neuroticism or depression in moderate drinking mothers in comparison with abstinents. Literary sources are contradictory on this issue. Whereas Lipton (18) shows in the study that moderate drinking is connected with the factor which consequently weakens the effect of stress on the evocation of depression or removes this stress altogether, Paschall, Freisthler, \& Lipton (19) do not find any differences between moderate drinkers and abstinents. We

Table 2. Factors of mother-child relation

\begin{tabular}{|l|l|c|c|c|c|}
\hline \multicolumn{2}{|l|}{} & N & m & SD & $\begin{array}{c}\text { F(d.f.=1; 2997) } \\
\text { p }\end{array}$ \\
\hline \multirow{2}{*}{ Maternity burden } & abstinent & 498 & -0.143 & 1.022 & $\mathrm{~F}=11.428$ \\
& moderate c. & 2.502 & 0.009 & 0.981 & $\mathrm{p}<0.05$ \\
\hline \multirow{2}{*}{ Love for child } & abstinent & 498 & 0.054 & 1.069 & $\mathrm{~F}=1.251$ \\
\cline { 2 - 6 } & moderate c. & 2.502 & 0.002 & 0.962 & n.s. \\
\hline \multirow{2}{*}{ Concerns about child } & abstinent & 498 & 0.208 & 1.089 & $\mathrm{~F}=34.906 \quad \mathrm{p}$ \\
\cline { 2 - 5 } & moderate c. & 2.502 & -0.069 & 0.961 & \\
\hline
\end{tabular}


did find higher level of emotional lability with moderate drinking group when compared with abstinents in our data. However, the two groups differed significantly in many issues even though the neuroticism was included as a covariate in the model. We can assume only a limited effect of the emotional lability.

Two other explanations are rather suspicious. Alcohol intoxication as well as alteration (damage) of cognitive functions are not probable due to the low frequency and amount of drunken alcohol in the group of moderate drinking women. Even though we cannot exclude for instance an injury of a child that happened after (sporadic) alcohol consumption, it is very improbable that such consumption could influence the mother's behaviour and activities with the child, as well as regular hygiene.

The hypothesis about the influence of moderate alcohol consumption on the alternation (damage) of cognitive functions is not supported in the literature. The damage of brain tissues and cognitive functions does not occur with usually tolerated alcohol consumption and the effect of alcohol on cognitive functions was proved in much older subjects only $(10,20,21)$. On the other hand, studies prove a higher influence of alcohol on the deterioration of memory and attention with women than men (22).

Laplace, Chermack and Taylor's (23) research supports selfcontrol hypothesis. They record higher aggression in moderate drinkers against the opponent even in comparison with abusers.

\section{CONCLUSIONS}

Our results based on exploring three areas of a mother's behaviour towards her child relatively congruently prove the assumptions that the behaviour of moderate drinking mothers differs from the behaviour of abstaining mothers, despite the difference being relatively subtle. An explanation of this difference can be reduced neither on the acute effect of alcohol on behaviour, nor on the long-term effect of a small amount of alcohol on the changes of cognitive and executive functions. Differences found, however, cannot be unambiguously reduced to the higher emotional lability of moderate drinking mothers. We incline to the hypothesis that the explanation of these subtle differences can be found in the change of self-regulation comprising emotional and volitional factors, which together influence lifestyle of the mothers in general. This assumption casts the requirement of further study of not only psychological but also socio-cultural context of moderate alcohol consumption.

\section{Acknowledgements}

This work was supported by the Institute for Research on Children, Youth and Family [MSM0021622406] and the Czech Science Foundation [GA406/07/1196].

\section{REFERENCE}

1. Reynolds K, Lewis B, Nolen JD, Kinney GL, Sathya B, He J. Alcohol consumption and risk of stroke: a meta-analysis. JAMA. 2003 Feb 5;289(5):579-88. Erratum in: JAMA. 2003 Jun 4;289(21):2798.
2. Mukamal KJ, Conigrave KM, Mittleman MA, Camargo CA Jr, Stampfer MJ, Willett WC, et al. Roles of drinking pattern and type of alcohol consumed in coronary heart disease in men. N Engl J Med. 2003 Jan 9;348(2):109-18.

3. Anttila T, Helkala EL, Viitanen M, Kåreholt I, Fratiglioni L, Winblad B, et al. Alcohol drinking in middle age and subsequent risk of mild cognitive impairment and dementia in old age: a prospective population based study. BMJ. 2004 Sep 4;329(7465):539.

4. Pernanen K. Alcohol in human violence. New York: Guilford; 1991.

5. Lowe G. Pleasures of social relaxants and stimulants - the ordinary person's attitudes and involvement. In: Warburton DM, editor. Pleasure: the politics and the reality. Chichester: Wiley; 1994. p. 95-108.

6. Hall W. Changes in the public perceptions of the health benefits of alcohol use, 1989 to 1994. Aust N Z J Public Health. 1996 Feb;20(1):93-5.

7. Baum-Baicker C. The psychological benefits of moderate alcohol consumption: a review of the literature. Drug Alcohol Depend. 1985 Aug;15(4):305-22.

8. Peele S, Brodsky A. Exploring psychological benefits associated with moderate alcohol use: a necessary corrective to assessments of drinking outcomes? Drug Alcohol Depend. 2000 Nov 1;60(3):221-47.

9. Kubicka L, Csémy L, Kozený J. Prague women's drinking before and after the 'velvet revolution' of 1989: a longitudinal study. Addiction. 1995 Nov;90(11):1471-8.

10. Meyerhoff DJ, Bode C, Nixon SJ, de Bruin EA, Bode JC, Seitz HK Health risks of chronic moderate and heavy alcohol consumption: how much is too much? Alcohol Clin Exp Res. 2005 Jul;29(7):1334-40.

11. Rosett HL, Weiner L, Lee A, Zuckerman B, Dooling E, Oppenheimer E. Patterns of alcohol consumption and fetal development. Obstet Gynecol. 1983 May;61(5):539-46.

12. O'Connor MJ, Paley B. The relationship of prenatal alcohol exposure and the postnatal environment to child depressive symptoms. J Pediatr Psychol. 2006 Jan-Feb;31(1):50-64.

13. Walpole I, Zubrick S, Pontré J, Lawrence C. Low to moderate maternal alcohol use before and during pregnancy, and neurobehavioural outcome in the newborn infant. Dev Med Child Neurol. 1991 Oct;33(10):875-83.

14. O'Callaghan FV, O'Callaghan M, Najman JM, Williams GM, Bor W. Maternal alcohol consumption during pregnancy and physical outcomes up to 5 years of age: a longitudinal study. Early Hum Dev. 2003 Apr;71(2):137-48

15. Willford J, Leech S, Day N. Moderate prenatal alcohol exposure and cognitive status of children at age 10. Alcohol Clin Exp Res. 2006 Jun;30(6):1051-9.

16. Eiden RD, Edwards EP, Leonard KE. Mother-infant and father-infant attachment among alcoholic families. Dev Psychopathol. 2002;14(2):25378.

17. Edwards EP, Eiden RD, Leonard KE. Behaviour problems in 18- to 36-month old children of alcoholic fathers: secure mother-infant attachment as a protective factor. Dev Psychopathol. 2006;18(2):395-407.

18. Lipton RI. The effect of moderate alcohol use on the relationship between stress and depression. Am J Public Health. 1994 Dec;84(12):1913-7.

19. Paschall MJ, Freisthler B, Lipton RI. Moderate alcohol use and depression in young adults: findings from a national longitudinal study. Am J Public Health. 2005 Mar;95(3):453-7.

20. Stampfer MJ, Kang JH, Chen J, Cherry R, Grodstein F. Effects of moderate alcohol consumption on cognitive function in women. N Engl J Med. 2005 Jan 20;352(3):245-53.

21. Reid MC, Van Ness PH, Hawkins KA, Towle V, Concato J, Guo Z. Light to moderate alcohol consumption is associated with better cognitive function among older male veterans receiving primary care. J Geriatr Psychiatry Neurol. 2006 Jun;19(2):98-105.

22. Mumenthaler MS, Taylor JL, O'Hara R, Yesavage JA. Gender differences in moderate drinking effects. Alcohol Res Health. 1999;23(1):55-64.

23. Laplace AC, Chermack ST, Taylor SP. Effects of alcohol and drinking experience on human physical aggression. Pers Soc Psychol Bull. 1994 Aug;20(4):439-44. 